\title{
BIODIVERSITY AND ECOSYSTEM SERVICES
}

\section{Baruti Abdala Yussufu \\ Sumy State University, Ukraine}

Many societies today have technological capabilities undreamed of in centuries past. Their citizens have such a global command of resources that even foods flown in fresh from all over the planet are taken for granted, and daily menus are decoupled from the limitations of regional growing seasons and soils. These developments have focused so much attention upon human-engineered and exotic sources of fulfillment that they divert attention from the local biological underpinnings that remain essential to economic prosperity and other aspects of our well-being. These biological underpinnings are encompassed in the phrase ecosystem services, which refers to a wide range of conditions and processes through which natural ecosystems, and the species that are part of them, help sustain and fulfill human life.

In addition to the production of goods, ecosystem services support life through the following: purification of air and water; mitigation of droughts and floods; generation and preservation of soils and renewal of their fertility; detoxification and decomposition of wastes; pollination of crops and natural vegetation; dispersal of seeds; cycling and movement of nutrients; control of the vast majority of potential agricultural pests; maintenance of biodiversity; protection of coastal shores from erosion by waves; protection from the sun's harmful ultraviolet rays; partial stabilization of climate; moderation of weather extremes and their impacts

Although the distinction between "natural" and "human-dominated" ecosystems is becoming increasingly blurred, we emphasize the natural end of the spectrum, for three related reasons. First, the services flowing from natural ecosystems are greatly undervalued by society. For the most part, they are not traded in formal markets and so do not send price signals that warn of changes in their supply or condition. Furthermore, few people are conscious of the role natural ecosystem services play in generating those ecosystem goods that are traded in the marketplace. As a result, this lack of awareness helps drive the conversion of natural ecosystems to human-dominated systems, whose economic value can be expressed, at least in part, in standard currency. The second reason to focus on natural ecosystems is that many human-initiated disruptions of these systems -- such as introductions of exotic species, extinctions of native species, and alteration of the gaseous composition of the atmosphere through fossil fuel burning -- are difficult or impossible to reverse on any time scale relevant to society.

Moving our attention from the moon back to Earth, let us look more closely at the services nature performs on the only planet we know that is habitable. Ecosystem services and the systems that supply them are so interconnected that any classification of them is necessarily rather arbitrary. Here we briefly explore a suite of overarching services that operate in ecosystems worldwide.

Humanity obtains from natural ecosystems an array of ecosystem goods - organisms and their parts and products that grow in the wild and that are used directly for human benefit. Many of these, such as fishes and animal products, are commonly traded in economic markets. The annual world fish catch, for example, amounts to about 100 million metric tons and is valued at between $\$ 50$ billion and $\$ 100$ billion; it is the leading source of animal protein, with over $20 \%$ of the population in Africa and Asia dependent on fish as their primary source of protein. Soil represents an important component of a nation's assets, one that takes hundreds to hundreds of thousands of years to build up and yet very few years to be lost. Some civilizations have drawn great strength from fertile soil; conversely, the loss of productivity through mismanagement is thought to have ushered many once flourishing societies to their ruin . Today, soil degradation induced by human activities afflicts nearly 20 percent of the Earth's vegetated land. In addition to moderating the water cycle, as described above, soil provides five other interrelated services. First, soil shelters seeds and provides physical support as they sprout and mature into adult plants. The cost of packaging and storing seeds and of anchoring plant roots would be enormous without soil. Human-engineered hydroponic systems can grow plants in the absence of soil, and their cost provides a lower bound to help assess the value of this service.

Ecosystem services are being impaired and destroyed by a wide variety of human activities. Foremost among the immediate threats are the continuing destruction of natural habitats and the invasion of non-native species that often accompanies such disruption; in marine systems, overfishing is 
a major threat. The most irreversible of human impacts on ecosystems is the loss of native biodiversity. Society would clearly profit by further investigation into some of the following broad research questions so that we might avoid on Biosphere 1, the earth, unpleasant surprises like those that plagued the Biosphere 2 project: What is the relative impact of various human activities upon the supply of ecosystem services? What is the relationship between the condition of an ecosystem - that is, relatively pristine or heavily modified - and the quantity and quality of ecosystem services it supplies? To what extent do ecosystem services depend upon biodiversity at all levels, from genes to species to landscapes? To what extent have various ecosystem services already been impaired? And how are impairment and risk of future impairment distributed in various regions of the globe?

The human economy depends upon the services performed "for free" by ecosystems. The ecosystem services supplied annually are worth many trillions of dollars. Economic development that destroys habitats and impairs services can create costs to humanity over the long term that may greatly exceed the short-term economic benefits of the development. These costs are generally hidden from traditional economic accounting, but are nonetheless real and are usually borne by society at large. Tragically, a short-term focus in land-use decisions often sets in motion potentially great costs to be borne by future generations. This suggests a need for policies that achieve a balance between sustaining ecosystem services and pursuing the worthy short-term goals of economic development. 